\section{G389(P) ENHANCING COMMUNICATION AND TRAINING OPPORTUNITIES IN PAEDIATRICS}

${ }^{1} \mathrm{H}$ McDermott, ' $\mathrm{L}$ Duthie, ${ }^{1} \mathrm{~L}$ Kelly, ${ }^{1} \mathrm{H}$ Vawda, ${ }^{1} \mathrm{C}$ Hine, ${ }^{1} \mathrm{~A}$ Darbyshire, 'S Brothwell, ${ }^{1} \mathrm{E}$ Syrimi, ${ }^{1} \mathrm{E}$ Reunis, ${ }^{1} \mathrm{H}$ Coakley, ${ }^{2} \mathrm{H}$ Goodyear. ${ }^{1}$ Paediatrics Trainee Committee, West Midlands, West Midlands, UK; ${ }^{2}$ School of Paediatrics, Health Education England West Midlands, West Midlands, UK

\subsection{6/archdischild-2020-rcpch.333}

Aims Historically, communication about regional training and educational opportunities relied on emails from the school administrator, programmes or assessments teams. This resulted in not all being aware of information. Therefore, in 2018, the Head of School (HoS) and trainees' committee (TC) devised innovative approaches.

Methods The TC and HoS had meetings to discuss methods of improving communication and standardising trainees' expectations, particularly regarding the Annual Review of Competency Progression (ARCP). We created and implemented an 'ARCP checklist' for trainees and trainers of expected eportfolio entries, which was aligned with $\mathrm{RCPCH}$ requirements in 2018-19.

We planned and implemented a regional trainees' website and investigated various communication methods to enhance trainee engagement and minimise time spent searching for information.

In August 2019, we distributed a snapshot survey via social media (Whatsapp groups and Facebook) and at protected teaching days using online platform Survey Monkey to assess trainees' experience and gain feedback.

Results The regional trainees' website has clearly laid out information updated weekly by the TC. This includes educational and research opportunities, courses, teaching resources and how to apply for academic and less than full time training, plus return to work programmes.

All regional paediatricians receive a monthly newsletter produced by the HoS with essential information including training updates, educational courses and opportunities, supervisor training and trainee-led research. We created a Twitter account to further disseminate information.

Feedback The survey had 41 responses (14\% of trainees) with at least one response from each training year. Most (17) responses were from ST4-5. Of the 37 (90\%) who had used the website, 35 (94\%) found it 'quite' or 'extremely useful'. The ARCP checklist was frequently mentioned as one of the most useful changes implemented. 38 (93\%) read the newsletter and the majority (86\%) found it 'quite' or 'extremely useful'. Fewer (54\%) trainees were aware of the Twitter account. $30 / 38$ trainees $(79 \%)$ reported the changes had improved trainee experience compared to before these resources were available.

Conclusion By embracing technology and close liaison between TC and school board, our regional communication and trainee experience has been significantly enhanced. We recommend this to all paediatricians.

\section{G390(P) A PEER LED REFLECTIVE DEBRIEFING PILOT PROJECT}

SM Harris, EM Nickerson. Paediatrics, Aneurin Bevan University Health Board, Newport, UK

10.1136/archdischild-2020-rcpch.334

Aim To evaluate the experience paediatric trainees had of debriefing sessions following resuscitations and to improve access and experience of debriefing sessions by the implementation of peer led reflective debriefing sessions for paediatric staff.

Method An online questionnaire was circulated to all paediatric trainees in Wales showing poor availability of debriefing sessions. A pilot reflective debriefing project was implemented using the Medical Trauma Resilience Management (MedTRiM) model. The MedTRiM model is adapted from the TRiM model used in the Royal Marines. It is a proactive, peer delivered and evidence based human resource management initiative for supporting individuals following exposure to potentially traumatic events and including a psychological scoring system for attendees. Ground rules and onward referral mechanisms were identified. Monthly hour long sessions were arranged over a 6 month period. A MedTRiM training course was organised to ensure sustainability and recruit faculty. Cases were referred by consultant of the week and staff invited via email.

Results Our survey of Paediatric trainees in Wales from January 2015, enquiring about experience of debriefing following paediatrics resuscitations, showed that $82 \%$ had been involved with child deaths. Only $17 \%$ had been invited to a debrief $>75 \%$ of the time and no debriefing had been offered $52 \%$ of the time. $57 \%$ said they would have benefited for psychological well being.

During the pilot project, four new clinical cases and one case follow up meeting were planned over the six month period. 34 people were invited with a total of 15 staff attending, across departments and disciplines. No one scored above the threshold for referral. Feedback included the benefits of meeting other team members after the event, having the time set aside to share the emotional impact and becoming aware that their feelings were 'normal' reactions.

Conclusion Following on from the pilot, improvements noted include: having a more robust case reporting system; improved documentation of contact details of those present at the resuscitation; ad hoc meetings rather than regular monthly meetings due to the time lag; and protected time being prioritised for these sessions. Further training courses and establishing a peer support group are planned.

\section{G391(P) POSITIVE EVENT REPORTING AND LEARNING FROM EXCELLENCE}

A Oliver, H Green, A Munro, A Green, K Riley, K Cathie. Southampton Childrens Hospital, University Hospital Southampton, Southampton, UK

\subsection{6/archdischild-2020-rcpch.335}

Aims Favourable Event Report Forms (FERFs) are used to allow staff to report events where things went well (in comparison to adverse events). Recently, a FERF team was established to try and extend the impact and learning from FERFs using Appreciative Inquiry (AI). This is an approach using a process to engage people in focussing on strengths and positive experiences in order to build on these in a collaborative and creative way to create system change.

Methods Each month a FERF of the month is awarded. In order to take on the AI approach, the nominator and receiver for the FERF of the month were engaged in an appreciative inquiry conversation with a member of the FERF team. This followed the Definition, Discovery, Dream, Design and Destiny structure to draw out more details about the event and why 